\title{
Tempo no museu e o museu no tempo
}

\author{
Time in the museum and the museum in time
}

\author{
Renata Monteiro $^{1}$ • Guaracira Gouvêa ${ }^{2}$
}

\begin{abstract}
Resumo: Este estudo discute o tempo mediante o lugar e objeto nos museus de ciência e técnica, apresentando diferentes abordagens teóricas a partir de uma perspectiva física e social. Este aporte subsidia a análise de discursos do público espontâneo do Museu de Artes e Ofícios, que expõe objetos históricos relacionados ao universo do trabalho, técnicas e ofícios do período pré-industrial brasileiro. Os discursos analisados mediante a metodologia do Discurso do Sujeito Coletivo tiveram como ponto de partida as categorias monocultura do tempo linear e a ecologia das temporalidades, baseadas na crítica da razão metonímica. As ideias centrais destacam a produção industrial na configuração do tempo linear, com perda da criatividade e identidade com o objeto produzido, bem como, a padronização refletida no modo de vida, o que confere a emergência de um conflito dialético no qual se busca conjugar diferentes ritmos temporais.
\end{abstract}

Palavras-chave: Espaço-tempo. Museu de ciência e tecnologia. Museu de artes e ofícios. Monocultura do tempo linear. Ecologia das temporalidades.

\begin{abstract}
This paper examines the time in relation to the place and the object in the museums of science and technology, presenting different theoretical approaches from a physical and social perspective. This contribution analyses spontaneous speech collected from the public in the Museum of Arts and Crafts, which exhibits historical objects related to the world of work, techniques and crafts of the Brazilian pre-industrial period. The analysis of the speech using the methodology of the Discourse of the Collective Subject allowed categories to emerge: the monoculture of linear time and the ecology of temporalities, both based on the Critique of Metonymic Reason. The central ideas highlight the loss of creativity and identity with the object in the linear time setting of industrial production, as well as the standardization reflected in the way of life, which raises the crisis of a dialectical conflict that seeks to combine different time rhythms.
\end{abstract}

Keywords: Space-time. Museum of science and technology. Museum of arts and crafts. Monoculture of linear time. Ecology of temporalities.

\footnotetext{
${ }^{1}$ Instituto de Nutrição Josué de Castro, Universidade Federal do Rio de Janeiro (UFRJ), Avenida Carlos Chagas Filho, 373, Edifício do CCS, Bloco J, $2^{\circ}$ andar, Cidade Universitária, Rio de Janeiro, RJ, Brasil. Email:

$<$ renatas_monteiro@hotmail.com>

${ }^{2}$ Programa de Pós-Graduação em Educação, Universidade Federal do Estado do Rio de Janeiro (UNIRIO), Rio de Janeiro, RJ, Brasil.
} 


\section{O lugar do tempo nos museus de ciência e tecnologia}

O museu, segundo Van-Praët e Poucet (1993), tem como especificidade a articulação dos elementos lugar, objeto e tempo, que deve ser observada nas diferentes formas de apresentar a informação. Uma dessas formas é denominada exposição, bem como, sua lógica de articular lugar, tempo e objeto - que caracteriza, historicamente, o tipo de museu ao qual estamos nos referindo. Knauss (2003) considera que é possível, por meio da discussão da lógica de exposição, por exemplo, aproximar a história dos museus e a história das coleções (objetos), sobretudo quando estamos tomando como referência os museus baseados em acervo histórico, como é o caso de nosso estudo que se desenvolve no Museu de Artes e Ofícios de Belo Horizonte, oriundo da tradição enciclopedista que alia museu, coleção e conhecimento.

Como Valente (2003) nos informa, é importante ressaltar que a lógica da exposição começa a ser revista quando, no século XVIII, os museus são abertos ao grande público - abertos à observação de qualquer pessoa -, e as suas coleções, antes organizadas em função das demandas da pesquisa, dos pesquisadores e dos artistas, começam a ser lidas por esse público. Nesse momento, a exposição pública de coleções adquire caráter educativo e de ampliação de conhecimento da população, pois necessitava tornar inteligível o que estava exposto por suas coleções, reafirmando a perspectiva enciclopedista. Esse movimento origina demandas educativas para o museu que refletem e refratam na perspectiva de Bakhtin (1986), em sua concepção de se expor ao olhar de muitos, e faz com que os profissionais de museu repensem seu caráter social e as formas de organizarem as exposições, assim surgem os setores e programas educativos voltados para o público em geral.

A história dos museus de ciência e tecnologia apresenta esse movimento quando, como nos indica McManus (1992), é alterado o papel das coleções de objetos históricos e as exposições passam a ter como foco a divulgação de ideias e conceitos científicos por meio de aparatos interativos com objetivo de facilitar a comunicação com o público em suas interações com as exposições. Desta forma, há uma intensificação do papel educativo dos museus, e as antigas exposições, nas quais todo o acervo era exibido, foram, aos poucos, substituídas por seleções representativas de cada temática abordada. Os museus dos Estados Unidos eram famosos por usarem aparatos midiáticos e reconstituições de ambientes (dioramas), que facilitavam a compreensão das temáticas, tornando as exposições mais inteligíveis e educativas (GARCÍA BLANCO, 1999; MARANDINO et al., 2008).

Ao final do século XIX, a maneira de expor passou a ser pensada pela separação entre o conteúdo das coleções científicas dos museus e sua apresentação pública, com a organização de exposições temáticas de caráter didático, de modo que:

As coleções não ficavam mais expostas à exaustão, uma vez que o momento do desenvolvimento das ciências impunha a seleção dos objetos para apresentações temáticas. A identidade entre museu e exposição se desfaz, embora a forma das exposições acompanhasse as novas concepções científicas”. (VALENTE, 2003, p. 23)

Orientar a exposição de coleções pautadas no paradigma hegemônico da área de conhecimento do museu significa "a retomada da função científica e patrimonial do museu" 
(VAN-PRAËT, 2003, p. 34). O enfoque nos processos, e não nos objetos, é uma característica dos museus de ciências naturais do século XIX, mas não só desses, pois isto definiu uma perspectiva de pensamento que norteou muitas ações, inclusive as educativas.

Quando nos detemos nos processos, e não nos objetos, estamos colocando em discussão a imaterialidade, tendo em vista, por exemplo, que nos museus de história natural - ao se passar do paradigma da sistemática para o da evolução, o que interessa é dar testemunhos que representem esse paradigma, reorganizando as formas de apresentar os testemunhos. $\mathrm{Ou}$ seja, o que está em pauta é o conceito de evolução, patrimônio imaterial.

No caso dos museus ciência e técnica, Jacomy (2007) apresenta um argumento para a entrada da imaterialidade, quando considera que os aparatos mecânicos têm seu funcionamento autoexplicável, isto é, as estruturas são visíveis e tangíveis. Em contrapartida, no caso das maquinas elétricas, sejam de geração de movimento ou de transmissão de informação, para se entender seu funcionamento, é necessário compreender o fenômeno associado ao seu funcionamento. Então, novamente, entra em pauta a imaterialidade e, nesse momento, para esse autor, aparece de forma mais marcante a demanda por mediação, seja por meio de textos verbais, imagéticos ou textos verbais orais, e a necessidade pela mediação humana se estabelece.

Atualmente, a linguagem dos museus contemporâneos precisa ser expressa por diferentes textos, disponibilizando a articulação entre lugar, objeto e tempo. Indica novas concepções de objeto (material - imaterial); de patrimônio tangível e intangível; de espaço edificado ou natural; de memória, ampliando nosso conceito de museu e de exposição. Seguramente, tanto o deslocamento das coleções para os processos, como a possibilidade de uso e de ocupação de lugares diferenciados por diversos recursos midiáticos contemporâneos geraram novas articulações entre lugar, objeto e tempo, agora entendidos de forma mais ampliada. Esse movimento de mudança da cultura museal busca atender às novas demandas educacionais do museu e, assim, estabelecem um movimento de uma outra cultura museal, caracterizada por práticas, por objetos materiais e imateriais repensados.

Nesse movimento, a ciência que explica como são os processos ganha importância e os science centers são criados para apresentar e ser uma das formas de representação da Ciência. Essa opção não é só educacional, isto significou uma maneira de repensar as formas de produzir e apresentar o conhecimento científico.

No entanto, esse movimento não abandona os objetos, estes continuam representando a cultura material das ciências, da técnica e da tecnologia e a própria história dos science centers; a materialidade do objeto está associada a aspectos simbólicos do fazer científico e tecnológico e à época desse fazer. Isto significa que, a partir do tangível, chega-se ao intangível, da descrição do objeto à explicitação dos processos.

Os museus, todavia, não estabeleceram, no mesmo período histórico, novas lógicas de exposições; e convivem, até hoje, diferentes museus com suas formas particulares de exposição, que dependem de sua temática, de suas coleções, do uso de recursos das tecnologias de informação e comunicação, entre outros. Mesmo considerando essa diversidade, todos os museus têm seu caráter educativo expresso na intencionalidade de suas exposições, de seus programas e de sua organização, articulando lugar, objeto e tempo.

Quando estamos nos referindo à articulação entre lugar, objeto e tempo, podemos trazer à discussão os seus correspondentes nas ciências da natureza: espaço, matéria e tempo. Observando esses léxicos, é fácil perceber que o único que se mantém é o tempo. O lugar é a 
(re)significação social do espaço; o objeto é resultado das transformações da matéria ou representa seus processos de transformação. Mas e o tempo, o que é? O museu, instituição da idade moderna (BENCHETRIT, 2003), lugar de guarda da memória por meio da conservação da cultura material é, por isso, guardião do tempo. Mas, de que tempo estamos falando?

\section{O tempo e a racionalidade moderna: o tempo físico}

Para apresentarmos nossos apontamentos e reflexões acerca do tempo, inicialmente, nos apoiaremos na percepção temporal elaborada na perspectiva da modernidade ocidental; para tal, se faz necessária uma releitura bibliográfica que traga contribuições de diferentes autores de diversas áreas de conhecimento, por meio de breves considerações.

O tempo é uma das categorias mais controversas nas ciências humanas, sociais e naturais do mundo ocidental, segundo pensadores de diferentes épocas e tendências - é "o problema crucial do realismo, pois como nos diz Leibniz, o tempo é a ordem de sucessão das coisas, de forma que sem as coisas não existiria tempo" (POPPER, 1976, p. 17, tradução nossa). Para Santos (1976, p. 41), "as coisas são os eventos e as suas tramas; o tempo o transcurso, a sucessão dos eventos e sua trama; e o espaço o lugar material da possibilidade dos eventos". Assim, problematizar o tempo, sem considerar o espaço e a matéria e a relação entre eles, torna-se tarefa impossível. Historicamente, essa relação é o desafio epistemológico das ciências naturais e sociais e, assim, de nós humanos.

Em nosso cotidiano, todos nós temos consciência da passagem irreversível do tempo, pois amamos e odiamos; nascemos, vivemos e morremos. Para nós, contemporaneamente, o tempo é infinito e tem um sentido, adquirindo um caráter absoluto e progressivo. Muitas narrativas são contadas no sentido de tornar o tempo reversível, isto significa reviver o passado e viver o futuro; são inúmeros os contos, as poesias, os filmes que versam sobre o tempo reversível, todas eles considerados de ficção. Os conceitos de passado, presente e futuro foram pensados considerando-se que existe uma flecha para o tempo, ou seja, um sentido para o tempo. Ele flui em um único sentido, o tempo não consegue andar para trás. Ou será que consegue? Para Coveney e Highfield (1983, p. 19),

É pertubador, mas em muitas teorias científicas, nas quais a direção do tempo não faz diferença, existe pouco apoio para encarar o tempo através do senso comum. Os grandes suportes da ciência moderna, tais como a mecânica de Newton, a relatividade de Einstein e a mecânica quântica de Heisenberg e Schrödinger, parecem funcionar igualmente bem com o tempo andando às avessas. Para essas teorias, os acontecimentos registrados em um filme seriam perfeitamente plausíveis, independentemente do sentido da projeção.

Para Whitrow (1989) e Fraser (1987), foi a tradição judaico-cristã que estabeleceu o tempo linear irreversível. A partir do nascimento e da morte de Cristo por crucificação, que constituem eventos que, segundo a crença cristã, não poderiam se repetir. A civilização ocidental toma o tempo como linear e progressivo, bem como, a existência de um passado e um futuro. 
Dessa maneira, a flecha do tempo constitui-se em uma escolha cultural e não encontra verificação empírica nas teorias de Newton, de Einstein e de Heisenberg e Schrödinger, mas criou condições para o pensamento histórico, para o estudo da ocupação do espaço, para a teoria da evolução de Darwin, para o estudo da evolução geológica do planeta Terra e para evolução do Universo.

A cosmologia moderna baseia-se na teoria geral da relatividade, considerada como a bela teoria da física. A relatividade geral conduz a uma síntese extraordinária ao relacionar o espaço com o tempo e a matéria, mas segue a tradição da dinâmica clássica de Newton, uma vez que não concede ao tempo nenhum sentido privilegiado. Não inclui, pois, a segunda lei da termodinâmica. (PRIGOGINE, 1996, p. 267)

O que acarretaria a consideração da segunda lei da termodinâmica? Significa considerar os fenômenos naturais, em sua maioria, como irreversíveis, como: a inexorável morte dos seres vivos, a queima de papel, a destruição do meio ambiente. A segunda lei nos indica que, em qualquer processo, se perde energia em forma de calor, e que ela não consegue ser recuperada; essa perda irreversível está ligada à passagem do tempo e nos remete a uma grandeza denominada entropia - medida da capacidade de mudança. $\mathrm{O}$ aumento de entropia indica um aumento da desordem e poderia nos encaminhar para um desaparecimento inexorável na desordem (COVENEY; HIGHFIELD, 1986, p. 30).

O grupo de pesquisa liderado por Ilya Prigogine (1996), em seus trabalhos com termodinâmica do não-equilíbrio, mostrou que a ordem pode surgir da desordem, considerando um paradigma denominado auto-organização: “[...] a auto-organização mostra que a segunda lei da termodinâmica não só proporciona uma flecha para o tempo, como tem dentro de si as sementes e os desenhos dos ciclos temporais que utilizamos para discernir o mundo que nos cerca" (PRIGOGINE, 1996, p. 31).

Isto implica, por exemplo, admitir a possibilidade da teoria da evolução. No entanto, alguns dilemas continuam quando se pensa a flecha do tempo. Um deles é a do tempo irreversível, associado aos fenômenos que ocorrem no mundo microscópico descrito pela mecânica intemporal. Segundo Coveney e Highfield (1986, p. 207), Boltzmann descobriu uma parte da solução desse dilema, pois estudos vinculados ao campo do caos dinâmico poderiam dar possíveis respostas. No entanto, ainda não estão resolvidos, no campo das ciências da natureza, os problemas associados à concepção de tempo linear e progressivo que se opõem à de tempo eterno, inviabilizando a volta ao passado e a ida ao futuro. Assim, para continuarmos nossa apresentação pautada em uma perspectiva moderna, precisaremos refletir sobre como as outras áreas pensam o tempo.

\section{A racionalidade moderna no tempo social e histórico}

De acordo com Elias (1998), na formação da estrutura da personalidade, se experimenta a ideia de tempo em seu caráter coercivo, quando a sensibilidade é moldada à autodisciplina no processo civilizador do habitus social para o desempenho do papel adulto, estamos falando de tempo social. Dessa maneira, membros de uma organização social, a fim de definirem posições 
e trajetórias, traçam sucessões de acontecimentos com reaparecimentos regulares criando modelos sequenciais. A noção do tempo se construiria ao longo da evolução humana, pautada no caráter instrumental de orientação, a partir de um saber adquirido e transmitido pela sucessão de gerações. Um saber ambivalente, que tende a regular a experiência humana, ao passo que denota uma condição de sobrevivência, entendida como "patrimônio do saber social acumulado pelas gerações" (ELIAS, 1998, p. 33).

Geertz (1989) analisa a temporalidade na cultura balinesa, a qual considera desenvolvida a tal ponto, que seria difícil compreendê-la a partir de escalas ocidentais. Para o autor, a premissa da diversidade permite, ao estudo da cultura, identificar os padrões culturais pelos quais os indivíduos de diferentes sociedades se orientam por meio de símbolos que conferem significados às suas vivências. A necessidade humana de orientação, como a que permite aprofundar características individuais, seriam formuladas diferentemente de uma sociedade para outra, ainda que, embora, reapareçam sendo os problemas de caráter existencial universal e as soluções dadas diversas, uma vez que humanas. Em sua ótica, os símbolos são "construídos historicamente, mantidos socialmente e aplicados individualmente", outorgando uma padronização cultural socialmente estabelecida com a qual nos defrontamos desde a infância (GEERTZ, 1989, p. 228).

Koselleck (1998) reflete sobre a capacidade de os conceitos se generalizarem e transcenderem no tempo, de modo que seria possível falar de uma história dos conceitos para compreender o formato da modernidade. Os conceitos articulariam experiências sociais na formação de redes discursivas de longo prazo. Para o autor, o que faz a aceleração do tempo histórico uma característica da modernidade é a distância entre o espaço de experiência e o horizonte de expectativas. Assim, ao mesmo tempo em que a modernidade instaura a dimensão da ruptura e a possibilidade de transformação histórica, acumula um contínuo de conceitos que tende a se perpetuar por gerações.

De acordo com Elias (1998), a observação dos fenômenos físicos e a materialização de dispositivos artificiais de medição do tempo, como relógios e calendários, tomam dimensão na prática das sociedades humanas como mecanismos de coerção. O que se deve, entre outros fatores, à dissociação do tempo no plano físico e no plano social, assim como, à separação entre "natureza" e "sociedade", conforme considera:

A contínua ampliação das sociedades humanas no interior do universo "físico", alheio ao homem, contribuiu para estimular um modo de falar que sugere que "sociedade" e "natureza" ocupariam compartimentos separados, impressão esta que foi reforçada pelo desenvolvimento divergente das ciências naturais e das ciências sociais. Todavia, o problema do tempo coloca-se em termos tais que não podemos esperar resolvê-lo se explorarmos suas dimensões física e social independentemente uma da outra. (ELIAS, 1998, p. 38)

Uma das marcas da modernidade é o advento do relógio mecânico, criado por Christiam Huygens, no século XVII, que possibilitou uma imagem da natureza mecânica e previsível e a separação do tempo natural do tempo social. O relógio, então, passou a ser o regulador das práticas sociais, e não mais os ciclos naturais. Apesar de o relógio funcionar a partir de oscilações periódicas, ele fez crescer a ideia de um tempo progressivo, linear e infinito, que é referendado 
com a construção do calendário gregoriano, que impôs um ritmo social e não natural para as práticas sociais. Essa concepção de tempo orienta toda a produção de conhecimento da época. Está contida em uma forma de pensar a história, bem como no conceito de periodização, elaborado no século XVIII, que implica admitir conceitos de passado, presente e futuro que têm, em seu âmbito, os conceitos de progresso e utopia. Nessa perspectiva, agindo no presente se poderia influenciar o futuro, construir um devir, pensamento característico da modernidade. Desta forma, "é impossível explorarmos as dimensões física e social do tempo independentemente uma da outra" (ELIAS, 1998, p. 38).

De acordo com D’Amaral (2003, p. 31), no contexto do tempo linear, comumente rejeitamos o acaso, que deveria, a seu ver, ser positivado. O autor considera que o acaso conferiria ritmo ao mundo, expondo uma diferença a partir da qual percebemos o tempo, marcado por uma incessante produção de acasos, entendidos como "exercício da liberdade de Deus", e que, ao irromper, apresenta "a máxima potência de poder não ser”, tal como expõe:

O acaso não é, portanto, o que deve ser evitado, mas, pelo contrário, o que deve ser positivado. A irrupção do acaso dá ritmo ao mundo. Quando um acaso irrompe, uma diferença se apresenta, e é assim que percebemos o tempo. E percebemos por causa da incessante produção de acasos que é o exercício da liberdade de Deus. Percebemos algo como tempo porque há um ritmo, uma ruptura de continuidades. Quando um acaso irrompe de surpresa, o que poderia não ser se afirma. Nessa máxima potência, o tempo é a nossa percepção de que o que é originalmente, quer dizer, provém de uma origem que não se dá linearmente como uma reta sem interrupção, mas segundo ritmos, diferenças, ao acaso, afirmando a máxima potência de poder não ser. (D'AMARAL, 2003, p. 31)

Tendo em vista a dimensão que podem adquirir as considerações acerca da percepção temporal na modernidade, optamos por um recorte que possibilite a análise de lógicas distintas, permeadas pela perspectiva da racionalidade moderna, mais precisamente, a crítica da razão metonímica, no sentido de repensar o tempo e seus desdobramentos em um campo de pesquisa.

\section{As categorias de análise: monocultura do tempo linear e ecologia dos saberes}

Santos (2007) entende a racionalidade ocidental como uma razão indolente, cuja indolência seria responsável pelo desperdício de experiências sociais. A razão indolente se apresentaria de duas principais formas: a razão proléptica e a razão metonímica. Segundo o autor, a razãa metonímica compreende todas as formas de pensamento único, que tomados como referência se imporiam às partes. Esta racionalidade subjaz ao conhecimento tanto filosófico quanto científico produzido, sobretudo, nos últimos duzentos anos no contexto sociopolítico de consolidação do estado liberal, compreendendo: as revoluções industriais, o desenvolvimento do capitalismo, do colonialismo e do imperialismo. Desta forma, a rąãa metonímica pode ser entendida como 
herança de uma racionalidade ocidental moderna, significativamente influenciada pela ciência, articulada por meio de cinco monoculturas, dentre as quais, a monocultura do tempo linear.

Assim, a razão metonímica não reconhece a pluralidade de percepções temporais existentes na diversidade de experiências sociais em curso no mundo, o que acarreta um desperdício espaço-tempo restrito à inteligibilidade da monocultura do tempo linear. Esta racionalidade seria responsável pela produção da não-contemporaneidade do contemporâneo, considerado naturalmente atrasado. O autor cita Koselleck (1985 apud SANTOS, 2007, p. 109) no que concerne à percepção da não-contemporaneidade do contemporâneo, ou seja, comumente, se considera como contemporâneo apenas uma parte reduzida do simultâneo - mas, se distancia da assertiva de Koselleck ao considerar que deixa de problematizar que "nesta assimetria se esconde uma hierarquia, a superioridade de quem estabelece o tempo que determina a contemporaneidade" (SANTOS, 2007, p. 110).

Em nosso estudo, a monocultura do tempo linear é tomada como referencial de análise, considerando, também, o seu contrário, ou seja, a ecologia das temporalidades, entendidas na perspectiva da diversidade de concepções e códigos temporais. Neste sentido, a pesquisa analisou percepções acerca do tempo a partir de entrevistas com o público em visita espontânea ao Museu de Artes e Ofícios. A seguir, apresentamos, de forma sintética, os referenciais citados - adaptado de Santos (2007).

Monocultura do tempo linear: ideia de que a história tem sentidos e direção únicos e conhecidos. Formulado nos últimos duzentos anos em forma de: progresso, revolução, modernização, desenvolvimento, crescimento, globalização. A ideia de tempo linear é a de que, na frente do tempo, seguem os países centrais do sistema mundial, e, com eles, os conhecimentos, as instituições e as formas de sociabilidades que neles dominam.

Ecologia das temporalidades: A ideia de tempo linear é entendida como uma entre muitas concepções de tempo, que se distinguem entre as culturas em diferentes códigos temporais, como: concepções de pontualidade, continuidade, descontinuidade, tempo reversível, tempo irreversível, e outros.

\section{O campo da pesquisa: Museu de Artes e Ofícios}

O Museu de Artes e Ofícios (MAO) se localiza na cidade de Belo Horizonte, e se baseia na exposição do acervo histórico relacionado aos instrumentos do universo do trabalho, técnicas e ofícios (MUSEU DE ARTES E OFÍCIOS, 2010). O museu apresenta peças originais do século XVIII ao século XX em dois prédios paralelos da antiga estação de trem da cidade, atualmente tombados e restaurados. O museu foi aberto ao público em 2006 sendo, portanto, um museu do século XXI. Entre os objetos estão instrumentos e utensílios do trabalho do período pré-industrial brasileiro em que se insere a produção, os fazeres, os ofícios e as artes que deram origem a algumas profissões, tal como, "ferramentas, utensilios, máquinas e equipamentos diversos que, individualmente ou em conjunto, conduzem cada visitante a uma identificação com o universo do trabalho ali referenciado" (MUSEU DE ARTES E OFÍCIOS, 2010).

Ainda que não seja a priori o objeto sobre o qual nos debruçamos nesta pesquisa, concordamos com Santos (1998), segundo o qual, na produção de sentidos, os objetos históricos dos museus são selecionados e organizados a partir de critérios e narrativas determinados por leituras contemporâneas, constituindo-se como um espaço de disputas políticas e conflitos simbólicos. 
Para Meneses (1994), o termo semióforo cunhado por Pomian (1997 apud MENESES, 1994, p. 18) busca designar objetos de mediação de ordem existencial, situados entre o visível e o invisível, em outros espaço-tempo e faixas de realidade. O autor destaca Braudrillard (1968 apud MENESES, 1994, p. 19), que teria rompido com a ideia de objeto antigo como "a-funcional", uma vez que, ressignifica o tempo. Assim, o objeto histórico nos museus seria de ordem ideológica, e não cognitiva, ainda que o considere como um instrumento ou fonte preciosa para compreensão da sociedade que o produziu e o reproduziu por malhas de mediação. Assim, o significado de um objeto semióforo se alteraria de acordo com a época e com o olhar de quem o contempla. Tanto o olhar como o tempo do olhar seriam datados historicamente.

Sobre a interatividade no MAO, é importante ressaltar que o espaço dispõe de "quiosques multimídias" espalhados ao longo do percurso, que permitem o visitante aprofundar o tema. Segundo Screven (1993 apud CHELINI; LOPES, 2008, p. 231), seria necessário um olhar cauteloso em relação à interatividade nos museus, pois, mesmo que represente um potencial instrumento de comunicação, pode, por outro lado, contribuir para a distração do visitante e a perda da linha de raciocínio e reflexão. $\mathrm{O}$ autor argumenta que a interatividade deve ser um meio, e não um fim. Atenta para o fato de que a interação não ocorre apenas com aparatos manipuláveis, mas, também, por processos mentais, ou seja, há interação por meio da contemplação, ainda que o indivíduo permaneça estático. Assim, consideramos que o MAO privilegia a contemplação do seu acervo por meio da exposição de instrumentos históricos do universo do trabalho, utilizando recursos tecnológicos como meios de comunicação com o público.

Em relação aos níveis de interatividade, com base em Wagensberg (2000 apud CHELINI; LOPES, 2008, p. 232), consideramos mais presentes, na exposição, os níveis de interatividade mental e cultural, a primeira relacionada ao instrumento e a técnica em determinado cotidiano de trabalho, e a segunda, às identidades coletivas, com aproximação de aspectos de âmbito local/regional. Apresenta, pois, com menor ênfase, a interatividade manual, representada pelos quiosques multimídia.

\section{Opções metodológicas e o perfil do público}

A metodologia da pesquisa se baseou em Lefèvre e Lefèvre (2005), a partir do instrumento teórico metodológico de análise o "Discurso do Sujeito Coletivo" (DSC). A opção pela DSC se confirma quando o entendemos como um instrumento capaz de contribuir para a análise dos discursos do público participante, com o objetivo de descrever e analisar pensamentos, ideias, crenças e opiniões. Foram realizadas entrevistas semiestruturadas; a transcrição das falas forneceu dados para análise do discurso individual ou coletivo dos sujeitos. Desta forma, foram utilizadas três figuras metodológicas: (i) expressões-chave: trechos literais transcritos que funcionam como matéria-prima para as ideias centrais e ancoragens; (ii) ideias centrais: descrevem, de maneira sintética, o sentido das expressões-chave; e (iii) ancoragens: indicam relações com a teoria ou a corrente de pensamento que o sujeito compartilha, sendo, muitas vezes, manifestações inconscientes que estão subjacentes às práticas cotidianas (LEFÈVRE; LEFÈVRE, 2005, p. 25-27).

O público da pesquisa se configurou pelo perfil familiar, com prevalência de pais e/ou mães com filhos, cônjuges e/ou amigos, em visita espontânea. Os entrevistados eram abordados ao término da visita e encaminhados a uma sala localizada na entrada do prédio, 
em um espaço destinado a guardar pertences. As cadeiras disponíveis no local possibilitaram a acomodação em um ambiente mais reservado. Algumas informações relativas à faixa etária, nível de escolaridade e residência podem contribuir para a compreensão do perfil dos 26 sujeitos participantes da pesquisa.

Em relação à faixa etária, a maioria dos entrevistados declarou idade entre quarenta e cinquenta anos - nove em um universo de 26 participantes; com idade até vinte anos, foram entrevistados seis sujeitos; entre vinte e trinta anos, foram cinco; o mesmo número foi recorrente entre trinta e quarenta anos, e, com mais de sessenta anos, participou apenas uma pessoa. Em nível de escolaridade, foi possível identificar 13 sujeitos com formação relativa ao Ensino Médio; os outros 13 teriam passagem pelo Ensino Superior, sendo dois destes pós-graduados. Em relação à área de residência, 15 declararam residir no Estado de Minas Gerais; oito na capital e sete no interior; 11 entrevistados declararam residir em outros estados como: São Paulo (quatro), Bahia (dois), Ceará (dois) e Distrito Federal (três).

\title{
O discurso do público dos Museu de Artes e Ofícios sobre o tempo
}

Conforme exposto anteriomente - o referencial teórico, as categorias de análise, as opções, o percurso e os instrumentos metodológicos, o perfil do público pesquisado, bem como, as características do MAO - é apresentado, a seguir, o resultado da pesquisa, na seguinte sequência: ideia central, expressões-chave e ancoragem.

\section{DSC 1. Ideia Central:}

\section{o modo de produção altera a relação com o objeto produzido}

\begin{abstract}
Expressões-chave:
Antigamente era tudo mais demorado, né? A coisa era mais a produção em baixa escala, né? Então as pessoas se envolviam com aquilo e isso limitava o acesso de várias pessoas aquele tipo de bem produziido, aí começa com a questão industrial que vai ampliar esse acesso, né? Você produz mais rapidamente, você troca a qualidade ou aquela forma de um trabalho totalmente envolvida por um trabalho que é por partes, cada pessoa faz uma etapa do trabalho. Ali não, você vê que quem começa aquilo vai fazer aquilo até o final, conbece o trabalbo que tá faz̧endo, a pessoa vê 0 objeto que ela fež, na indústria você vai ter trabalhadores que vão fažer uma infima parte do trabalho ele vê depois pronto, mas ele não se identifica com o objeto pronto, né? A gente viu, assim, antigamente como tudo era feito a mão, tinha uma certa diversidade, a gente vê uma torneira ali com uma boca de pato e tal, então você que tinha um espaço para criatividade. Antigamente tinha espaço de criação da pessoa que produzia, hoje a concepção da criação não é no momento da produção, é antes.
\end{abstract}

Neste discurso se observa a relação do tempo com os modos de produção; considera que a produção pré-industrial conferia maior identidade do trabalhador com o objeto produzido, participando de todo o processo. $\mathrm{O}$ advento da industrialização e a demanda por uma produção mais rápida e em larga escala diminuiu os custos da produção, ao passo que conferiu 
certo distanciamento do trabalhador com o objeto por ele produzido. O discurso relaciona a produção em baixa escala com a identidade dos trabalhadores, e a produção em larga escala à perda desta identidade. Outra consideração recai no fato de o modelo de produção em larga escala interferir no processo criativo, uma vez que os objetos feitos à mão possibilitam certa criatividade, a exemplo da torneira com "boca de pato". Com esta mudança, o processo criativo de concepção dos objetos passa a ser determinado antes da produção, e não durante. A criatividade e a identidade perdem espaço para a padronização, o que confere perda de autonomia dos trabalhadores.

\title{
DSC 2. Ideia Central:
}

\section{a vida, hoje, é padronizada, você já sabe tudo que vai acontecer no seu dia}

\begin{abstract}
Expressões-chave:
Eu acho que se perdeu e não foi muito pouco não, foi bastante. Hoje eu estava pensando correndo nessas galerias como que a nossa vida hoje é padronizada, você acorda de manhã e você já sabe tudo que vai acontecer no seu dia. Não tem gesto que você vê, assim, de um broto de uma planta, de um pássaro que veio tomar banho no rio; eu vivi isso aquilo me traz̨ia boas recordações, hoje você não tem, as suas ações são mecânicas. Você acorda de manhã as suas coisas são padronizadas até a sua alimentação é padroniz̧ada.
\end{abstract}

Segundo D'Amaral (2003), a racionalidade grega, que influenciou a universidade ocidental, privilegia o ordinário, que se apresenta como logos, conhecimento verdadeiro, que legitima o tempo linear e se distancia da perspectiva de ruptura, entendida como o que não pode ser. A valorização da previsibilidade e da repetição remonta a ideia de um tempo único e determinístico. O ordinário seria uma ocorrência tal como o acaso, no entanto, não apresentaria potencial no qual implique suas opções - escolhas por outros itinerários. Assim, observamos a ideia de padronização do tempo e a previsibilidade do modo de vida, de forma que, conforme discorre, "você acorda de manhã e você já sabe tudo que vai acontecer no seu dia". Desta forma, o discurso identifica a lógica do tempo na perspectiva da monocultura do tempo linear, ao passo que aponta a existência de outras temporalidades associadas à ecologia das temporalidades que comportam, por exemplo, a irrupção do acaso ou o que não é a priori previsível, tal como o "nascimento de uma planta" ou a "visita de um pássaro".

\section{DSC 3. Ideia Central:}

o tempo acelerado leva à busca por um ritmo de vida mais lento.

\footnotetext{
Expressões-chave:

Então, talvez seja mais difícil ver as vantagens de retornar, mas eu acho que aqui já se vê algumas pessoas querendo uma vida, assim, menos acelerada, fažer as coisas com mais calma, ao invés de comprar tudo pronto fazer alguma coisa, preparar. Então a gente tá voltando a isso você não paga para fažr, você vai e faz. Então é a forma de você, não tem o ganho do dinheiro, mas você deixa de gastar. Ter tempo significa vocêpoder fazer comida, pintar a casa. Acho que tem essa ideia de retorno e
} 
eu acho interessante eu vejo assim, acho que essa coisa do tempo acelerado do excesso de informação e aquela coisa do ritmo acelerado, isso cria uma ansiedade um stress muito grande. Então é um pouco assim, você vai faz̧er e sentir o que tá faz̧endo, ter tempo para fazerer eu acho que isso tá virando já uma necessidade.

Segundo Fabian (1983), o tempo se apresenta enquanto poder de dominação no plano físico, pois, ao ser compartimentado, condiciona, arbitrariamente, à sua medição, negligenciando outros elementos temporais. O autor investe na dimensão política do tempo, que, numa progressão linear, considera, como atrasados, saberes e fazeres que portem outras dimensões temporais. A partir das considerações do autor, ao nos aproximarmos do DSC 3, observamos a identificação da existência de uma lógica temporal a partir da qual se impõe uma progressão acelerada, que pode ser associada à monocultura do tempo linear. Por outro lado, considera a existência, ou, mesmo, pertinência, de outras temporalidades, tal como o retorno a ritmos mais lentos. No discurso, esta transição parece ser entendida como um movimento de retorno, mas que pode, também, representar, a partir de Santos (2007), um movimento de tradução, a fim de evidenciar a diversidade de experiências sociais em curso, o que se apresenta na perspectiva da ecologia das temporalidades. Desta forma, o discurso aponta a possibilidade de se conjugarem diferentes ritmos temporais, como, por exemplo, o interesse por produções imanentes ao próprio cotidiano, reforçando aspectos de identidade e autonomia. Em certa medida, é possível inferir um movimento dialético, ao passo que a monocultura do tempo linear leva ao esgotamento dos modos de vida pelo ritmo acelerado que impõe, tal como stress e ansiedade, o que conduziria ao seu contrário, ou seja, a busca por outras lógicas temporais pelo viés de uma ecologia das temporalidades.

\title{
DSC 4. Ideia Central: \\ hoje, é tudo muito rápido, se faz no aqui e agora, mas só tá pensando no depois
}

\begin{abstract}
Expressões-chave:
Eu acho que é por aí, é como conciliar o desenvolvimento com uma outra forma de vida mais lento e os seus beneficios, até a questão de como as pessoas se situam em relação ao tempo e a satisfação de faz̧er coisas inteiras, não faz̧er só um pedaço das coisas, ficar num giro assim num tempo muito rápido, né? Então, a gente não se dá conta de nada, não se consegue fazer nada com calma, não se consegue parar para fazer nada tranquilamente, é tudo muito rápido porque tá fazendo no aqui e agora, mas só tá pensando no depois, o aqui e agora praticamente não se faz, só se faz.pensando no depois. Então, acho que é isso ter um pouco mais de tempo de tranquilidade, acho que bá um conflito aí, entre o excesso de tecnologia e de informação que tá sempre jogando para frente, e aquela vontade também de ficar um pouco lá quando as coisas eram diferentes.
\end{abstract}

D'Amaral (2003) analisa a influência das tecnologias na sociedade, em um contexto no qual a velocidade, cada vez mais, se torna lugar comum. Assim, temos pressa e a obrigação de sermos contemporâneos. O autor indaga, no entanto, que esta necessidade de afirmação lhe parece uma obviedade, já que "naturalmente todo mundo sempre foi contemporâneo" (D’AMA- 
RAL, 2003, p. 17). Identifica a existência de uma inversão da lógica temporal, a partir da qual, cada vez mais, o virtual, ou o que pode vir a ser, toma dimensão no presente, antecipando e determinando acontecimentos. Deste modo, a tecnologia teria contribuído para a admissão do futuro como um tempo verdadeiro. A partir da leitura do DSC 4, observa-se a percepção do tempo em um ritmo acelerado, diante do qual, dificilmente, se produzem coisas com tranquilidade. Esta aceleração conduziria à antecipação do tempo futuro como um tempo verdadeiro, pois, conforme considera, "é tudo muito rápido porque tá fazendo no aqui e agora, mas só tá pensando no depois, o aqui e agora praticamente não se faz, só se fazpensando no depois". Desta forma, o que pode vir a ser se apresenta antecipando e determinando acontecimentos no tempo presente - de modo que, coloca-se um conflito a partir do qual nos situaríamos entre a condição de dar respostas ao excesso de tecnologia e informação que nos impulsiona para frente e a vontade de retornar aos benefícios de um modo de vida mais lento no qual se possa, por exemplo, fazer coisas por inteiro.

\section{Considerações}

A percepção do público se apresentou mediante a identificação da monocultura do tempo linear enquanto um tempo predeterminado e absoluto, pelo advento do modo de produção industrial. Por outro lado, em um processo dialético, identificamos percepções relacionadas à ecologia das temporalidades, com a positivação do acaso e outros ritmos temporais. Os discursos destacam as influências do modelo de produção industrial na configuração do tempo linear, com perda da criatividade e da identidade com o objeto produzido. A padronização da produção teria reflexos na percepção temporal da sociedade, gerando um conflito, diante do qual tenderíamos, em função das novas tecnologias, a ampliar o futuro e reduzir o presente. O discurso aponta, ainda, a necessidade de se conjugarem diferentes ritmos temporais. Desta forma, a partir da análise dos discursos, foi possível construir quatro ideias-centrais: (i) o modo de produção altera a relação com o objeto produzido; (ii) a vida hoje é padronizada, você já sabe tudo que vai acontecer no seu dia; (iii) o tempo acelerado leva à busca por um ritmo de vida mais lento; (iv) hoje é tudo muito rápido, se faz no aqui e agora, mas só tá pensando no depois.

A exposição do MAO se baseia no acervo histórico a partir do qual se estrutura o processo de contextualização museológica. A exposição de objetos históricos, também entendidos como semióforos, parece ter contribuído para que os visitantes recorressem à memória, facilitando um deslocamento tempo-espaço. As exposições portariam, assim, a mediação existencial de outros espaços-tempos, outras faixas de realidade. Essa nuance foi observada na análise dos discursos, na medida em que os sujeitos ressignificavam o movimento entre passado, presente e futuro, comumente atrelado à identidade individual e coletiva.

Um aspecto na tática museográfica apresentada pelo MAO é o uso de figuras humanas em ações, nas atividades com os objetos de trabalho, seja no cenário expositivo ou nos vídeos interativos, o que nos parece ser um marcador importante, pois a relação com as ferramentas de trabalho e os produtos fabricados alienam menos os trabalhadores e lhes dão outra dimensão do tempo que eles podem controlar, diferentemente da produção industrial em escala.

Outro aspecto é que o espaço museográfico está atravessado materialmente por uma linha de metrô e de trem, e isso acarreta em transitar entre séculos diferentes, entre temporalidades diferentes. $\mathrm{O}$ antigamente ganha múltiplas temporalidades quando o trem passa por 
esse espaço. No entanto, as questões colocadas ao museu, pelas formas de pensar o tempo, estão centradas em como essas formas geram novas formas de pensar o museu, o patrimônio e as exposições, pois a questão do tempo está na origem da instituição museu. Caso levemos às últimas consequências a contração do tempo, para aonde irão os museus? Poderemos pensar em um museu só do presente, descartável a cada nova configuração das informações? Seria pensar o tempo não mais como um círculo - eterno retorno -, ou como uma reta orientada - progresso e devir -, mas, como nos indica Debray (1991, p. 71, tradução nossa), "um ponto - do aqui e agora, do consumo e do descarte".

\section{Referências}

BAKHTIN, M. Marxismo e filosofia da linguagem: problemas fundamentais do método sociológico na ciência da linguagem. São Paulo: Hucitec, 1986.

BENCHETRIT, S. A história representada: por que refletir sobre o dilema dos museus. In: BITTENCOURT, J. N.; BENCHETRIT, S. F.; TOSTES, V. L. B. (Org.). História representada: o dilema dos museus. Rio de Janeiro: Minc: MHN, 2003. p. 19-24.

CHELINI, M. J.; LOPES, S. G. B. C. Exposições em museus de ciências: reflexões e critérios para análise. Anais do Museu Paulista, São Paulo, v. 16, n. 2, p. 205-238, jul./dez. 2008. Disponível em: < http://www.scielo.br/pdf/anaismp/v16n2/a07v16n2.pdf >. Acesso em: 14 out. 2014.

COVENEY, P.; HIGHFIELD, R. A flecha do tempo. São Paulo: Siciliano, 1983.

D’AMARAL. M. T. Sobre tempo: considerações intempestivas. In: DOCTORS, M. (Org.). Tempo dos tempos. Rio de Janeiro: Jorge Zahar, 2003. p. 15-32.

DEBRAY, R. Cours de médiologie genénérale. Paris: Gallimard, 1991.

ELIAS, N. Sobre o tempo. Rio de Janeiro: Jorge Zahar, 1998.

FABIAN, J. Time and the other. New York: Columbia University Press, 1983.

FRASER, J. Time: the familiar stranger. Washington: Tempus, 1987.

GARCÍA BLANCO, A. La exposición, un medio de comunicación. Madrid: Akal, 1999. (Arte y estética, 55).

GEERTZ, C. Pessoa, tempo e conduta em Bali. In: A interpretação das culturas. Rio de Janeiro: Guanabara, 1989. p. 225-277.

JACOMY, B. Instrumentos, máquinas e aparatos interativos de ciência e tecnologia exibidos nos museus. In: VALENTE, M. E. A. (Org.). Museus de ciência e tecnologia: interpretações e ações dirigidas ao público. Rio de Janeiro: MAST, 2007. p. 15-24.

KNAUSS, P. História de coletivo e história de expositivo. In: BITTENCOURT, J. I.; BENCHETRIT, S. F.; TOSTES, V. L. B. (Org). História representada: o dilema dos museus. Rio de Janeiro: Minc: MHN, 2003. p. 35-142. 
KOSELLECK, R. Los estratos del tiempo: estúdios sobre la historia. Barcelona: Paidós, 1998.

LEFÈVRE, F; LEFÈVRE, A. M. C. Discurso do sujeito coletivo: um novo enfoque em pesquisa qualitativa. 2. ed. Caxias do Sul: Educs, 2005.

MARANDINO, M. et al. Aprendizagens em biologia a partir da visita ao museu de Zoologia da USP. In: ENSINO de biologia: fios e desafios na construção de saberes. João Pessoa: Editora da UFPB, 2008. p. 149-168.

McMANUS, P. M. Topics in museums and science education. Studies in Science Education, New York, n. 20, n. 1, p. 157-182, 1992.

MENESES, U. T. B. Do teatro da memória ao laboratório da história: a exposição museológica e o conhecimento histórico. Anais do Museu Paulista, São Paulo, v. 2, n. 1, p. 9-42, jan./dez. 1994. Disponível em: <http://www.scielo.br/pdf/anaismp/v2n1/a02v2n1. pdf >. Acesso em: 14 out. 2014.

MUSEU DE ARTES E OFÍCIOS. Disponível em: < http://www.mao.org.br/>. Acesso em: 6 jan. 2010.

POPPER, K. Unended quest: an intellectual autobiography. La Salle: Open Court, 1976.

PRIGOGINE, I. Dos relógios às nuvens. In: SCHNITMAN, D. F. (Org.). Novos paradigmas, cultura e subjetividade. Porto Alegre: Artes Médicas, 1996. p. 257-273.

SANTOS, B. S. A crítica da razão indolente. São Paulo: Cortez, 2008.

Gramática do tempo. São Paulo: Cortez, 2007.

SANTOS, M. Técnica, espaço, tempo: globalização e meio técnico-científico informacional. São Paulo: Hucitec, 1976.

SANTOS, M. S. Os museus, a memória e os novos meios de comunicação. Informare: Cadernos do Programa de Pós-graduação em Ciência da Informação, Rio de Janeiro, v. 4, n. 2, p. 6-16, jul-dez, 1998.

VALENTE, M. E. A conquista do caráter público do museu. In: GOUVÊA, G.;

MARANDINO, M.; LEAL, M. C. (Org.). Educação e museu: a construção social do caráter educativo dos museus de ciência. Rio de Janeiro: Access, 2003. p. 21-46.

VAN-PRAËT, M. A educação no museu : divulgar "saberes verdadeiros" com“coisas falsas”. In: GOUVÊA, G.; MARANDINO, M.; LEAL, M. C. (Org.). Educação e museu: a construção social do caráter educativo dos museus de ciência. Rio de Janeiro: Access, 2003. p. 47-62.

VAN-PRAËT, M.; POUCET, B. Les musées, lieux de contre-éducation et de partenariat avec l'école. Éducation et Pédagogie, Sèvres, n. 16, p. 22-29, 1993.

WHITROW, G. T. Time is history. Oxford: Oxford University Press, 1989. 